\title{
MUSEU E ARQUIVO COMO LUGARES DE MEMÓRIA
}

\section{RESUMO:}

Este estudo analisa a memória e o arquivo como lugares de memória a partir de autores como Nora (1993), Winter (2006), Huyssen (1996), Freud (1997), que contribuíram com a noção de memória aliada ao processo de esquecimento e ao museu como instituição de memória. Analisa-se ainda, a memória pela via do arquivo, a dimensão documental que encerra o acervo e a dimensão do conceito de arquivo, qual seja, a noção de arquivo que se efetiva a partir do "mal de arquivo" (Mal d'archive) em Derrida (200I) e Roudinesco (2006) e do processo de arquivamento pelo qual passa a instituição museológica.

\section{PALAVRAS-CHAVE:}

Memória. Lugares de memória. Arquivos. Museus. Mal de arquivo.

\author{
Suely Lima de Assis Pinto' \\ Universidade Federal de Goiás
}

\begin{abstract}
:
This study analyzes the memory and the archive as places of memory, according to authors such as Nora (1993), Winter (2006), Huyssen (1996), Freud (1997), who have contributed with the notion of memory associated to the process of forgetfulness and to the museum as institution of memory. It also analyzes the memory via the archive, the documental dimension that closes the collection, the archive, the notion of archive, which becomes effective from Mal D'Archive in Derrida (200I)and Roudinesco (2006) and the process of filing, by which the museological institution goes through.
\end{abstract}

\section{KEY-WORDS:}

Memory. Places of memory. Archive. Museum. Mal D’Archive.

\footnotetext{
I Doutora em História pela Faculdade de História da Universidade Federal de Goiás - FH/UFG (200 I I), Mestre em Educação Brasileira - Faculdade de Educação da Universidade Federal de Goiás - FE/UFG (2003), Especialista em Museologia pelo Museu Antropológico da Universidade Federal de Goiás - MA/ UFG (200I), Graduada em Artes Visuais - Instituto de Artes da Universidade Federal de Goiás - IA/UFG (1984).Arte-educadora, professora Adjunta do curso de Pedagogia, Campus Jataí/UFG.
} 


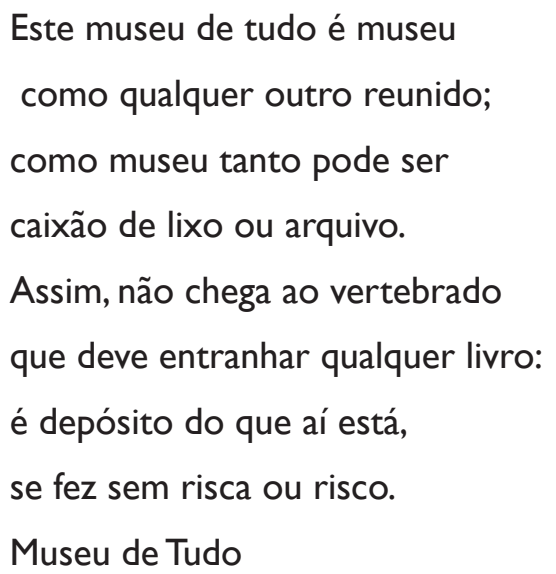

(João Cabral de Melo Neto)

Sabe-se que o museu, nesta primeira década do século $X X I$, não é apenas um espaço para lembrar e contar histórias, mas um espaço em que se constroem memórias. $O$ museu pode ser a lembrança de gente deixada pelo objeto, ou lembranças que incitam a busca de outras histórias: história de pessoas, história de lugares. Museu “lugares de memória".

Nora (1993) afirma que estamos passando por uma aceleração da história - aceleração do tempo, aceleração dos processos sociais - que seria uma oscilação cada vez mais rápida de um passado morto, algo desaparecido. Isso possibilita falar em memória justamente porque ela não existe mais. Há, nesse processo, uma curiosidade pelos lugares de memória, uma articulação em que a consciência da ruptura com o passado se confunde com a memória esfacelada. Para ele, há lugares de memória porque não há meios de memória, essa se torna um sentimento residual aos locais; ou seja, resíduos, restos de um passado já morto.

Os lugares da memória são, antes de tudo, restos. A forma extrema onde subsiste uma consciência comemorativa numa história que a chama, porque ela a ignora. É a desritualização de nosso mundo que faz aparecer a noção. O que secreta, veste, estabelece, constrói, decreta, mantém pelo artifício e pela vontade uma coletividade fundamentalmente envolvida em sua transformação e sua renovação. (...) os lugares de memória nascem e vivem do sentimento que não há memória espontânea, que é preciso criar arquivos, que é preciso manter aniversários, organizar celebrações, pronunciar elogios fúnebres, notariar atas, porque essas operações não são naturais (NORA, 1993: 12 - 13).

Os lugares de memória se fazem pela experiência, pelos restos, resíduos daqueles que vivem o lugar e pela preocupação em perpetuar uma memória que é viva, mas crê-se no seu desaparecimento, daí a necessidade de um espaço que reviva essa memória. Como no "museu de tudo", epígrafe desse texto, uma vontade incontrolável de criar arquivos gerados para a lembrança, para o desejo de não esquecer e não ser esquecido, memória que são restos, rastros de uma história.

Segundo Nora (1993), se a memória estivesse em permanente processo de rememoração, não haveria necessidade de lugares. No entanto, se a história sente a necessidade de criá-los é justamente porque ela corre o risco de se extinguir, ou seja, há o sentimento entre as minorias de que se não houver comemorações, a história os varreria. Deve-se habitar a memória para que não seja 
necessário lhe consagrar lugares. Mas se o que defendem não estivesse ameaçado, se estivessem realmente na lembrança vival, os lugares seriam inúteis.

Desta forma, Nora (1993, p. 13) compreende que, se não houvesse a história, mesmo que, a deformá-los ou a transformá-los, eles não se tornariam lugares de memória. É exatamente este movimento que os constitui "momentos da história arrancados do movimento da história" não mais inteiramente à vida, não mais inteiramente à morte, mas num incansável movimento de sentidos, de símbolos, entre a fantasmagoria que os constitui e os vestígios que os materializa na memória viva - como em Derrida (200I) ao pensar no arquivo que se constitui em favor dessa memória, e que, no limite sempre procura nos vestígios, na matéria, os restos, a fantasmagoria do arquivo que muitas vezes se desvela em sua origem - é este movimento que fará a memória ser tomada pela história, que fará a necessidade da memória ser uma necessidade de história.

A memória verdadeira, abrigada no gesto e no hábito, nos ofícios que transmitem os saberes do silêncio, nos saberes do corpo, é para Nora (1993) uma memória transformada por sua passagem em história. Uma memória psicológica, individual e subjetiva ao invés de social, coletiva, globalizante. Isto é, uma memória que se constitui de restos, mesmo diante de seu aspecto universalizante ela não perde sua singularidade que a faz única. Para esse autor, é uma memória que a faz diferente da memória arquivística, ou seja, na memória pautada na guarda excessiva de arquivos. Ela se apóia no traço, no material, no vestígio. A memória precisa ser vivida a partir de seu interior para que não sejam necessários esses suportes exteriores, ou seja, essa guarda infindável de arquivos. A obsessão pelo arquivo, que marca o contemporâneo surge exatamente dessa necessidade de arquivar, e isso afeta a preservação integral de todo o passado.

Essa relação exagerada ao processo de arquivar está no pensamento de Freud (1997) sobre o mal-estar na civilização. Para ele, o arquivo, a necessidade de arquivamento e lembrança é um mal-estar, uma pulsão, uma pulsão de morte2, que é ao mesmo tempo uma vontade de lutar, guardar, é também trazer o arquivo da memória à vida. Por isso, para esse autor, o passado nunca passa, pois no presente, estamos sempre rememorando o passado, trazendo à tona os restos.

O lugar de memória parece estar na contramão do excesso de arquivo que muitas vezes gera o mal de arquivo, onde há excesso de matéria, de material, de documentos e objetos, há também falta de escrita, de escritura3. Essa procura pela materialidade, pelo objeto, pelos vestígios, integra o corpus da maioria das instituições hoje. Para que se configurem em lugares de memória faz-se necessário esse trabalho de presentificação da memória, trazendo a vida e a experiência para os arquivos, para os objetos. É preciso trazer para o lugar de memória o sentimento de pertencimento no presente, em sua agoridade.

Não seriam ações de comemoração como bem lembrou Nora (1993), mas de subjetivação do espaço. Deixar vir os fantasmas de tempos diante de um não tempo, de um não-dito, de um não-lugar. Memórias de um grupo singular e não de um sujeito institucionalizado, eleito como detentor de poder corroborado pelos vestígios documentais institucionais4.

\footnotetext{
I Para Freud a memória está guardada e faz com que se entre muitas vezes no passado, quando isso ocorrer esse passado será sempre rememorada no presente.

2 É essa relação ligada a pulsão, que Derrida (200I) traz para a questão do arquivo, que se verá mais a frente desse estudo.

3 Para Roudinesco (2006), a escritura é processo de historicizar o documento, trazer a tona sua história, tornar acessível à pesquisa, confrontá-la, torná-la viva.

4 Isto é o que Roudinesco (2006, p. I0) chama de dogmatização do arquivo. Ela observa que se houver
} 
É essa a ótica referente à experiência, memória, vidas que circundam os acervos que Chagas (2006) apreende em seu estudo como a necessidade de perceber "uma gota de sangue em cada museu", quando faz uma paráfrase de Mario de Andrade. Para ele, aliada ao museu, a memória deveria conter "uma gota de sangue" e não ser apenas um mero reconhecimento de poder. Deveria ser "lugares de memória" a serviço de uma coletividade e não o privilégio de grupos economicamente abastados. Essa posição refere-se a uma memória que é construção, situada na dimensão inter-relacional entre os seres, e entre os seres e as coisas. E que os museus, mesmo sendo memória do poder, não deixam de trazer, de modo explícito ou não, um indelével "sinal de sangue". Sinal de subjetividades, singularidades, restos, fissuras que precisam ser explicitadas.

Observa-se que a maioria dos museus durante o século $X X$ construiu uma memória pautada no arquivamento, na guarda e patrimonialização dessa memória, cuja necessidade de preservar vai produzir as instituições culturais. Memória e patrimônio ligado ao boom da memória debatido por Winter (2006) que levou ao fenômeno da musealização. Isso ressalta o dogma ligado a figura do rememorante, ou a memória do poder. No contexto desse estudo memória é passado, restos e vestígios.

Nora (1993) lembra que o que se chama de memória nesta sociedade é uma constituição gigantesca e vertiginosa do estoque material daquilo que é impossível lembrar. Essa é também a posição de Derrida (200I) e Roudinesco (2006). É exatamente por isso, que a maioria das instituições que deveriam ser lugares de memória, constituem-se em simples depositário de objetos desprovidos de memória, de história, incapazes de falarem ao subjetivo.

Há um incentivo acelerado ao arquivamento de tudo, "o dever de memória faz de cada um o historiador de si mesmo" (NORA, 1993, p. 17), são as memórias singulares, que com o fim da memória-história, reclamam sua própria história. É preciso lembrar, mas cabe ao sujeito lembrar. É ele, em sua individualidade, que lembra, que guarda.

Há aqui um paradoxo se se pensar a guarda dessa memória que foi individual ou singular de um sujeito pois, de acordo com Roudinesco (2006) esse sujeito pensou a guarda de seu arquivo, de sua memória sob uma lógica, e esta nem sempre será a mesma, quando seguida por um arcôntico. Uma grande distancia entre o que foi pensado e o que foi constituído se instala nas inúmeras leituras e interpretações geradas no interior das instituições, causando uma fissura entre a memória e o arquivo da memória.

Para Nora (1993), quanto menos a memória é vivida coletivamente, mais ela tem a necessidade de homens particulares que fazem de si mesmos homens-memória. Ou seja, se se percebesse o seu pertencimento, os lugares se efetivariam mesmo como lugares de memória.

No entanto, esse não pertencimento ocorre justamente porque as produções históricas são diferentes daquela que se espera de uma memória. Ou seja, é necessário um esforço de lembrança para ressuscitar esse passado, atualizá-lo enquanto presente por meio "dos sintomas", abrindo aí uma fissura entre o passado e o presente. É a capacidade de perceber o "sinal de sangue”, que irá transformar o museu em "lugar de memória".

O que se observa aqui é a presença do conceito de lugar em duas vertentes diferentes. Primeiro em Nora (1993), cujo conceito de lugar são espaços so-

a negação do arquivo como memória subjetiva, ou como herança genealógica há o risco de conduzir ao delírio e a reconstrução do arquivo como dogma. "Sob esse aspecto, a ausência de vestígio ou a ausência de arquivo é tanto um vestígio do poder do arquivo quanto o excesso de arquivo". 
ciais, arquitetônicos, lugares que servem para comemorar, emblemáticos, como parques, cemitérios, museus, datas, que marcam algo que não é mais lembrado pelas pessoas, mas que para se tornar "lugar de memória" esse espaço precisa de uma relação que se efetiva entre o sujeito, sua afetividade e subjetividade e o espaço - sujeito que é lembrado pela memória do lugar e sujeito observador que se apropria desse espaço neste processo de subjetivação. $O$ segundo conceito de lugar se efetiva pela via da psicanálise, pensado a partir de Derrida (200I) e Roudinesco (2006) que é um lugar subjetivado, vinculado ao desejo. Como o lugar espacial pode ser um monumento comemorativo cujo não pertencimento do sujeito que o frequenta o transforma em um lugar comum, que se configura no esquecimento. O lugar da psicanálise abre elementos sintomais que possibilitam essa relação de pertencimento justamente pela capacidade de ser olhado pelo objeto, pelo lugar.

A percepção do passado é segundo Nora (1993, p. 30), a apropriação daquilo que se sabe não mais pertencer a sua individualidade; é uma acomodação sobre um objeto perdido. Daí uma necessidade de memória-espelho, não para que se refletisse aí a própria imagem, mas para procurar "o brilhar repentino de uma identidade impossível de ser encontrada”.

É neste universo que se encontra o historiador, sujeito capaz de impedir que a história seja somente história, e sim, possibilitar que os lugares de vestígios se transformem em lugares de memória. Lugares que se constituem simultaneamente em material simbólico e funcional. Lugares que bloqueiam o esquecimento, imortalizam a morte, deixa vir o que nos olha (DIDI-HUBERMAN, 1998), materializa o imaterial, dá sentido ao mínimo de sinais. É isso que os torna apaixonantes:

o lugar de memória é um lugar duplo: de excesso, fechado sobre si mesmo, fechado sobre sua identidade, recolhido sobre seu nome, mas constantemente aberto sobre a extensão de suas significações (NORA, 1993, p. 21).

É espaço de significações, de histórias vividas, experienciadas, marcadas pela historicidade, pelo "sinal de sangue". Museus, bibliotecas, arquivos, todos ao pôr em cena uma visão sobre determinado fato, acontecimento, personagem, não estão colocando uma história em si mesma, e sim, uma leitura possível e historicamente condicionada. É necessário reverter essa ação. No campo museal essa leitura significa olhar o objeto e ser olhado por ele. É trazer ao universo desses lugares históricos uma memória constituída de restos e, assim, possibilitar sua transformação em "lugar da memória".

Percebe-se com isso o quanto a memória tem sido alvo de debates, não só em espaços museais, mas em diferentes instâncias públicas e/ou particulares sob esta perspectiva do patrimônio. Ora possibilita a sua afirmação como memória e pertencimento ou memória-construção, e ora, no sentido simplório do termo, como memória/comemoração que é uma necessidade de historiar a memória que estava se esvaindo. É essa perspectiva ligada à memória e comemoração que na maioria das vezes se configura na constituição excessiva de arquivos.

Segundo Winter (2006), os anos 1980 impulsionaram os estudos sobre memória que, de alguma forma, estavam ligados ao interesse entre memória ou comemoração, como se viu também em Nora (1993), ou ao desejo de reapresentar ou legitimar narrativas chamadas, às vezes, de memória coletiva. E quando estes estudos são financiados por agentes ligados ao poder, as histórias reforçarão as credenciais para esse poder, como também observou Chagas (2006). 
No entanto, para Winter (2006), a memória coletiva não está apenas na esfera do poder. Diferentes comunidades possuem suas narrativas e reinvindicam uma identidade coletiva5, questão essa, também explicitada por Nora (1993)."Muitos grupos étnicos e minorias desprivilegiadas exigem seu direito à palavra, à ação e o direito de conquistar sua liberdade ou a sua autodeterminação" (WINTER, 2006, p. 70). Independente do Estado, estas minorias constroem sua própria história gerando uma memória coletiva. Ou seja, algumas ações se iniciam com o poder e para o poder, mas diante das lutas das comunidades em criar suas próprias narrativas, a preservação da memória vai além dessas esferas.

Huyssen (I996, p. I2), ao analisar a memória aliada ao esquecimento, afirma que houve uma "explosão ao discurso da memória como um sintoma cultural nas sociedades ocidentais", procurando, à medida que o fim do milênio se aproximava, voltar o olhar para trás numa ânsia de armazenar dados e informações. Esse processo era acompanhado por um profundo sentimento de crise articulado à crítica de que a sociedade se encontra doente, com amnésia. $O$ esquecimento foi desencadeado pela própria contemporaneidade e seu constante mal-estar; o medo de esquecer está associado ao desenvolvimento da escritura, do registro, de confiar na máquina que registra a memória (FREUD, 1997). É a confiança na máquina que registra e armazena dados, em detrimento da capacidade humana de re-memorar um evento.

Esse processo de esquecimento ou de amnésia também foi um desencadeador do boom da memória observado por Winter (2006), o qual cita diferentes fatores que impulsionaram este momento na década de 1980. Um deles seria o grande interesse ligado à memória e comemoração do holocausto e o desejo de "re-apresentá-lo". Estas manifestações desencadearam reflexões sobre que tipo de memória está contemplado nestes estudos. A política de identidade, criada e disseminada por narrativas do passado, e o desenvolvimento da tecnologia da informação, como bancos de dados audiovisuais, que deu uma nova forma de validação à noção de testemunho, são fatores que levaram ao boom da memória e, a partir daí, para a criação de arquivos e processos de informatização.

Interessante observar que este processo de informatização também pode ser associado ao fenômeno da aceleração, da musealização. Nessa sociedade da aceleração o museu também passa a musealizar tudo. Volta-se a idéia de museu de tudo, de um museu que tem seu tempo de guarda, de memória, de arquivamento. Como não se consegue preservar no tempo da aceleração, surge, nesse contexto, a necessidade de digitalizar, de converter em arquivo digital, e assim, tudo pode ser guardado. Criam-se os bancos de dados tanto de acervo material, por meio da imagem, como bancos de dados de sujeitos e suas histórias. Converte-se em outra linguagem que passa a fazer sentido, excesso de memória transformada e informatizada.

A memória ligada à noção de testemunho, segundo Seligmann-Silva (2006), descrita a partir de um evento catastrófico será sempre parcial, pois nunca dará conta da experiência do sobrevivente, memória do trauma. Ela está no limiar

5 Associada a essa questão percebe-se grande número de museus históricos e regionais criados no Brasil a partir da expansão dada pelo Instituto Brasileiro de Museus (IBRAM) na definição do campo da museologia. Várias comunidades que possuíam espaços de guarda de memória, casa de cultura, ou memoriais solicitaram seu credenciamento como museu. Neste sentido, houve também a expansão dos lugares que reinvidicam o estatuto de "lugar de memória". No site do IBRAM pode-se perceber essa dimensão dos "lugares" por seu texto de apresentação do que seja um museu:

"Os museus são casas que guardam e apresentam sonhos, sentimentos, pensamentos e intuições que ganham corpo através de imagens, cores, sons e formas. Os museus são pontes, portas e janelas que ligam e desligam mundos, tempos, culturas e pessoas diferentes". 
entre lembrar e esquecer, lembrar o evento crucial para uma comunidade/humanidade, esquecer o trauma, as cicatrizes. A partir da memória traumática, abrem-se caminhos para estruturação de museus que poderiam "transformar narrativas nacionais em narrativas de famílias, com apelo a um grande público de várias nacionalidades" (WINTER, 2006, p. 83). É um momento de expansão tanto para os estudos da memória quanto para sua musealização, considerando o efeito defendido pela musealização tradicional.

A ênfase nas questões da memória que se efetivou principalmente na década de 1980 abre caminhos para essa necessidade de preservação, que Huyssen (1996) analisa como sendo ações, procedimentos já conhecidos no trabalho dos museus e que parecem apontar para novas instâncias, abordando esse fenômeno cultural da musealização. Com isso, os museus passam a ocupar espaços bem maiores na cultura e experiência cotidiana apontando para uma obsessiva recuperação/musealização, da cidade, dos cenários históricos, da vida cotidiana, transformando o museu num paradigma das atividades culturais contemporâneas. Para ele, isso parece um paradoxo, pensar o sucesso do museu numa época em que a aceleração das ações cotidianas parece apontar para uma perda dos sentidos, perda de memória, provocando a amnésia.

Esse processo de transformação apresentado por ele é resultado de modificações pelas quais os museus passam no inicio do século $X X$ e que foram desencadeadas a partir dos museus modernos. As transformações no interior dos museus de arte e da obra de arte propriamente dita desencadearam tanto novas formas de pensar os espaços, como nova forma de utilização desse espaço, a partir da criação de bibliotecas, restaurantes, lojas no interior dos museus. Com isso, houve no interior das instituições uma reelaboração de sua estrutura física, tipológica e conceitual.

No entanto, essa perda da memória pode ser considerada como um não-lembrar, como uma negação daquilo que está intimamente recalcado. Está associado a um não-dito6 ou não-lugar. É esse universo de percepção (o recalque) que é aberto por Didi-Huberman (1998) quando associa a capacidade de ser olhado pelo objeto, ou Nora (1993) quando chama a atenção para a presença de um elemento externo aos vestígios que transformariam os museus em "lugares da memória", ou Chagas (2006) quando menciona a existência de uma "gota de sangue" nos museus a qual deve direcionar a percepção dos estudos de memória. Não é uma busca infindável pela preservação de um patrimônio cultural, mas a percepção dos "sinais de sangue" neles contidos. Os restos, os sintomas que constituem a memória.

\section{Desdobramentos do museu: entre a memória e o arquivo}

A ênfase na questão da memória abre caminhos para a criação de arquivos gerados no cotidiano daquele que lembra. $O$ lugar para esse arquivo se constitui, independente do que pode ser arquivado, em espaços culturais públicos ou privados, mas espaço-museu.

Para Huyssen (1996), museu é um efeito direto da modernização. Guarda de memória, do obsoleto, da história. Guarda do novo, que parece envelhecer a passos largos. Essa posição do autor remete ao modelo de museu do século XIX. Se se considerar as transformações pelas quais a museologia vivencia no século

6 Pollack (1989) afirma conter dentro da lembrança uma zona de sombra, de silêncio, de angústias, de "não-ditos". 
$X X$, perceber-se-á que o museu de arte - que se transformou num paradigma dos museus na primeira metade do século $X X$-transformou-se no modelo de museu desse mesmo século, o que desencadeou o processo de transformação nos museus que trouxeram outra compreensão do processo museológico e expositivo. Voltando à posição do autor, percebe-se que para ele os museus:

foram criados para serem instituições pragmáticas que colecionam, salvam e preservam, aquilo que foi lançado aos estragos da modernização. Mas ao fazer isso, o passado inevitavelmente seria construído à luz do discurso presente e a partir de interesses presentes [...] (HUYSSEN, 1996: 225).

Nesse sentido, pode-se considerar que o pragmatismo observado por ele se desconstrói diante da escritura desse arquivo, visto que, o pragmatismo é estabelecido pelo dogma, pelo poder, pela história centrada no acontecimento, no documento7 e a construção desse passado, no museu, já incorpora os métodos da historiografia recente. Ou seja, o passado é uma fabricação do presente, elaborado a partir de interesses presentes, a partir de uma atualização o passado é reelaborado a cada vez que se faz uma escritura.

Com base nessa construção do passado, segundo Huyssen (1996), o museu expõe uma dialética gravada em procedimentos de colecionar e exibir, ações estas perdidas por aqueles que celebram o museu como proprietário de bens inquestionáveis. Percebe-se que, mesmo diante dessa transitoriedade em seus processos museológicos e, mesmo sendo considerados por muitos como um espaço de dogmas inquestionáveis, o museu ainda "se mantém como um espaço e um campo para reflexões sobre a temporalidade, a subjetividade, a identidade, e a alteridade" (HUYSSEN, 1996, p. 226).

O museu incorporou, nesse processo, práticas e teorias que os auxiliaram a lidar com esse fenômeno cultural de musealização que o autor analisa como uma prática associada ao processo globalizador que, na verdade, nada mais é que o fenômeno da cultura como mercadoria e bem simbólico, ligado, por um lado, à aceleração das coisas cotidianas, em função da aceleração do tempo, e de outro, surgindo como uma instituição de guarda e preservação. E para entender esse paradoxo que se coloca, Huyssen (1996) traz a idéia da mercadoria; as instituições que tinham uma determinada função passam a incorporar novas funções, operando dentro de um circuito cultural determinado por uma rede de interesses e valores questionáveis.

Observa-se, no entanto, que essa realidade não abarca a maioria dos museus brasileiros. Museus que, na perspectiva de Lourenço (1999), foram criados sem nenhuma estrutura, não conseguem ultrapassar essa dialética que os colocaria num patamar capaz de transitar entre sua origem (processo de criação) e a nova museologia (novos elementos que se erigiram nos espaços museais). Frente a isso essa problemática lançada por Huyssen (1996) permite pensar as instituições de memória por outra perspectiva, visto que possuem funções e papéis que não são mais os tradicionais. Tem-se que considerar todo o processo de sistema da arte ligado aos interesses da instituição que preserva e da instituição que fomenta e mercantiliza o processo de musealização.

Ao analisar esse modelo de museu apresentado por Huyssen (1996), que seria um museu pós-moderno e se considerar a perspectiva de que a maioria dos museus brasileiros ainda não opera nessa lógica, pois se posiciona nos mo-

7 Considera-se aqui a partir de Roudinesco (2006) e Derrida (200I), que o documento, ao ser elaborado, ele se faz também a luz de interesses naquele momento, o arquivo é uma escolha. 
delos tradicionais do século XIX, verifica-se também as exceções. E é justamente essa exceção ligada aos novos museus, a essa esfera de mercantilização, da aceleração, analisada pelo autor, que é passível de ser percebida nas transformações ocorridas em diferentes museus de arte.

De um lado, tem-se os dogmas e, de outro, a ampliação que se constitui em duas direções: uma que tem o museu como instituição de memória e não só de preservação, e outra, que tem o museu como instituição do excesso, que é como o "museu de tudo" mencionado anteriormente. Percebe-se que essas duas direções se diferem entre si ao mesmo tempo em que se confundem no interior da instituição. A primeira segue a lógica inicial da museologia, que tende a achar na memória uma maneira de se modificar o discurso da preservação, e outra, como é o caso observado por Huyssen (1996), que tem na mercantilização da memória uma prática perversa, o seu excesso, o museu de tudo. Tem-se uma tendência de musealizar o próprio museu.É essa prática de memória que leva ao esquecimento.

Numa análise sobre esse processo de transformação que se opera no interior dos museus, sobre suas práticas, memória e preservação, memória e mercantilização, teremos, nesse contexto, uma terceira via que envolve essa prática e a concepção de memória. Ou seja, considerando os dois primeiros aspectos, este estudo traz a memória pela via do arquivo.

Interessante observar que para Huyssen (1996), os museus pós-modernos e em constante transformação têm modificado sua própria estrutura interna museológica; ao invés de grandes exposições permanentes estão se acentuando grandes exposições temporárias. Isso em função do interesse por megaexposição e de todo o aparato capitalista que a envolve. $O$ autor considera que na era do pós-moderno o processo de redefinição do museu vai além da dialética museu/modernidade - o museu não é mais guardião de tesouros e artefatos do passado, mas se aproxima do mundo do espetáculo, feiras, diversão de massa. Isto porque ele foi "sugado" pelo "distúrbio" da modernidade (sintoma), suas exposições são anunciadas como grandes espetáculos. E que, neste contexto, são de interesse capital até para a própria cidade.

Isso desencadeia um interesse comercial no processo de musealização, que nem sempre é parte das intenções políticas e sociais da cidade, mas que vê na abertura de uma exposição, apenas a possibilidade de uma expansão turística a partir daquele evento. Esta "lógica" aqui observada envolve não só o processo de construção de uma memória histórica, mas também seu arquivamento - a memória e a sua materialização por meio de vestígios e musealização, e ainda o processo de musealização envolto em interesses políticos, públicos e/ ou particulares, principalmente no que tange aos grandes eventos, gerando muitas vezes conflitos internos e externos em função dessa guarda e arquivamento.

Se se analisar o processo de criação dos museus de arte, ou as intenções originárias, e a distância na concretização desses ideais iniciais, e ainda, observando como agravante a falta de estudos, na área de museus de arte, e/ou a organização de um acervo que se constitui sem dispor de conceitos, de dados históricos, de compromissos sociais e éticos, de vasta bibliografia de apoio (LOURENÇO, 1999), percebe-se que para museus no cenário do interior brasileiro esta é a realidade que se efetiva. Ou seja, o acervo se constitui as expensas de sua própria identidade, constitui-se de excessos - excesso de arquivo, mas falta de arquivamento.

Os museus de arte brasileiros, segundo Lourenço (1999), estão unidos por uma vasta carência, que vem desde a sua implantação e, em alguns casos, permanecendo após a criação. Faltam pesquisas criteriosas, histórico de ativida- 
des relativo ao público e ao acervo, além de dados bibliográficos e patrimoniais. Muitas vezes, as exposições temporárias se constituem rotineiras, justamente pela falta de condições de expor o próprio acervo, (diferenciando aqui da análise de Huyssen (1996), cujas exposições temporárias se constituem em interesse e mercantilização com vistas em mega-exposição) outras vezes, os museus relegam a segundo plano a sua função comunicacional por ser inexistente um projeto de comunicação visual coerente com sua identidade.

É exatamente essa dinâmica que permeia o interior da maioria dos museus de arte, falta de condições espaciais para exposição de seu acervo, falta de autonomia financeira que conceda grandes alterações no escopo da instituição, falta de aquisição considerada significativa por aqueles que gerenciam seus acervos.Tudo isso faz com que esses pequenos museus se configurem em galerias a partir de uma política de editais de ocupações. Esta se torna a opção viável para uma dinâmica no interior do museu ao mesmo tempo em que essas ocupações se configuram também em doações. Ou seja, visualiza-se aí uma solução para aquisições, independente de uma política de fomento interna.

Muitas vezes a escolha do acervo a ser exposto, segundo Lourenço (I 999), está nas mãos e na opinião pessoal de alguém selecionado para tal função, ou seja, um curador convidado. Para ela, seria mais importante investir na formação de quadro técnico capaz de exercer essa função, visto que, por desconhecer a rotina e identidade do museu, este profissional fica impossibilitado de pensar uma política de seleção que possa contribuir com a tipologia da instituição. É importante ressaltar a necessidade de formação desse quadro pessoal independente de ter ou não curadoria externa, pois se acredita que essa questão seria amenizada por uma curadoria envolvida com a instituição em longo prazo.

O problema de indefinição de um acervo para os museus de arte nos remete ao poema de João Cabral de Melo Neto, epígrafe deste texto, pois a forma indiscriminada com que se abrem museus, desde a década de 1950 até esta primeira década do século $X X I$, geram vários "museus de tudo" em diferentes regiões brasileiras, mas cria-se também, no que se refere aos museus de arte, "tudo de museu", que abriga o mais complexo e diversificado acervo de arte tanto internacionais, quanto nacionais, regionais ou mesmo locais. $O$ "museu de tudo" de João Cabral é a realidade do museu brasileiro, principalmente os regionais, salvo, é claro, poucas exceções.

No entanto, no bojo do debate aqui empreendido, esse museu de tudo é ainda um museu-memória-arquivo, como museus que vão se configurando na contramão do que se espera deles. A memória no museu dar-se-ia justamente na formação de seu arquivo, ou, na falta deles, gerando tanto o mal de arquivo quanto seu apagamento. $O$ excesso de arquivo se configura em excesso de dados e a ausência total de escritura. É a impossibilidade de sua inscrição na cultura, aquilo que aqui se chamou de não-pertencimento diante daquilo que deveria ser sua história, sua memória. É um museu de um museu, cheio de vestígios, vazio de informação.

Para dar uma consistência ao trabalho no campo da memória, este estudo traz um viés diferente do que normalmente é utilizado pelo campo da museologia para se pensar o museu como instituição de memória, e que, a priori, está ligada à idéia de memória e patrimônio.A memória aqui debatida se dá por meio do conceito de arquivo em Derrida (200I), ou seja, analisa-se o mal de arquivo; o arquivo que é, ao mesmo tempo, instituidor e conservador, revolucionário e tradicional. Ele guarda, reserva de uma forma não natural, como uma lei a ser 
respeitada, uma ordem, que é do lugar, da família ou da instituição. Isto infere ainda a questão de poder também imbricada na instituição de arquivos; há uma lei, mas há também um poder.

O museu em sua constituição já lida com o campo entre excesso e falta de acervo, excesso de objetos, falta de informação. $O$ mal de arquivo é uma metáfora, uma cadeia de sucessão que está associada ao conceito freudiano de mal-estar, esse mal-estar provocado pelo excesso de dados e a ausência total de escritura, o silêncio. Excesso de escrita e falta de escritura.

\section{Arquivo e mal-estar}

Quando se tem o excesso de arquivos e a falta de escritura não tem como inscrever esse arquivo na cultura, pois não se tem a história, nem a escritura do evento. Para tanto, Derrida (200l) analisa como se efetiva o problema da escritura ou a falta dele com base no conceito de mal-estar em Freud, analisando a partir da pulsão de morte8 uma sobre-vida ao arquivo.

É importante considerar o conceito freudiano de mal-estar para se entender o processo no qual Derrida (200I) constrói a noção de arquivo. Ao se considerar o processo de arquivamento, ou o excesso de arquivo, se verá que para Freud (1997) são como a mente que guarda e conserva as camadas de histórias, gravadas como por camadas arqueológicas. A relação com essas histórias que podem tanto ser recalcadas, quanto serem afloradas diante da memória afetiva é que vai traçar os caminhos do indivíduo para uma sensação de felicidade. No entanto, a busca incessante de felicidade pode levar ao sofrimento, ao mal-estar. Ao analisar a fonte de onde o sofrimento provém, o autor cita como sendo três: o poder superior da natureza, a fragilidade de nossos próprios corpos e a inadequação das regras que procuram ajustar os relacionamentos mútuos dos seres humanos na família, no Estado e na sociedade (FREUD, 1997, p. 37).

Ele considera a terceira fonte de sofrimento como a mais forte. Refere-se ao relacionamento com outros seres humanos e às leis e normas criadas para conviver com esses seres, no Estado e na sociedade. Quando se percebe o insucesso neste campo, percebe-se também o mal-estar, a incompletude. Para Freud (1997) há uma insatisfação, é essa insatisfação que gera o mal-estar da civilização - esse mal-estar da humanidade que está em seu processo civilizatório, que está na forma como a humanidade suprimiu seus desejos, inibiu seus instintos e em como todo esse processo foi absorvido pelo superego (consciência).

\footnotetext{
8 Freud (1997) afirma que em Além do princípio do prazer a "compulsão para repetir e o caráter conservador da vida instintiva" atraíram sua atenção. E, partindo de especulações sobre o começo da vida, e sobre paralelos biológicos ele compreendeu que, assim como Eros havia também um instinto de morte "os fenômenos da vida podiam ser explicados pela ação corrente, ou mutuamente oposta, desses dois instintos" (p. 77). Os dois instintos estão vinculados a restrição de uma agressividade, no entanto, para ele, essa agressividade na natureza humana é necessária, pois é a relação entre a pulsão de morte e a pulsão de vida (Eros). Precisa-se da tensão existente entre essas duas pulsões para manter a vontade, o desejo; de lutar; de viver; de crescer; de fazer algo. Ele afirma também que diante deste impulso para a agressão, há uma presença constante do instinto libidinal.Vê-se, então, que a libido está também ligada ao instinto de agressão. Há, assim, uma indistinta ligação entre Eros (pulsão de vida) e a destruição (pulsão de morte) "o instinto de destruição, moderado e domado, e, por assim dizer, inibido em sua finalidade; deve, quando dirigido para objetos, proporcionar ao ego a satisfação de suas necessidades vitais e o controle de sua natureza.” (p. 80-8I). Para ele a evolução civilizatória consiste na luta entre Eros e a morte e essa representa a capacidade do indivíduo de tolerar essa tensão que se instaura.
} 
Diante disso, é possível afirmar que a insatisfação ou infelicidade é causada pelo processo de mal-estar na civilização gerado pelo próprio indivíduo diante de uma sociedade que ele mesmo criou. A não adequação a essa sociedade gera o sentimento de culpa. No entanto esse sentimento de culpa é para Freud positivo por se tratar de uma pulsão destrutiva que irá impulsionar o desejo pela mudança e será então organizadora dessa mudança. É essa relação que Derrida (200I) traz para a questão do arquivo.

Freud (1997) analisa a partir do mal-estar que o sujeito por não se adequar a uma sociedade criada por ele mesmo, que mesmo diante de regras rígidas, de controle, não se sente protegido, pelo contrário se sente desamparado, passa a vivenciar uma tensão entre o ego e o superego, entre vida (Eros) e morte. Essa tensão traz o sentimento de culpa, (que a priori deveria ser ruim) como bom no contexto exposto por Freud (1997), pois ao gerar uma pulsão destrutiva gera também uma re-significação da agressividade. Essa tensão e seu processo de superação é visto por Derrida (200I) como uma possibilidade de re-significar também a questão do arquivo. Percebe-se que a relação proposta por Derrida leva à compreensão da memória ligada ao traço9. Memória é um traço, um arquivo, uma escritura, que em Freud está associado a um estado de culpa. Derrida (200I) atualiza esse conceito elaborando uma ligação entre o conceito de mal-estar e o arquivo, criando a partir daí, o conceito de mal de arquivo.

Para Roudinesco (2006) Derrida aborda em mal de arquivo - a relação trágica e inquieta que se constrói frente ao arquivo - uma relação de dependência ou autoritarismo diante do espectro do arquivo e que exerce um dogma frente ao arquivado. Roudinesco (2006) chama a atenção para a obediência cega ao arquivo e a seu poder absoluto mostrando que isso leva à impossibilidade da história e a uma recusa do arquivo, ou ainda o contrário, o culto excessivo ao arquivo. Uma história quantitativa é também "destituída de imaginação e que proíbe que possamos pensar a história como uma construção capaz de suprir a ausência de vestígios" (ROUDINESCO, 2006, p. 9). Ou seja, acredita-se que se tudo está arquivado, a história já estaria escrita.

Trata-se aqui de uma falta e de um excesso na questão de arquivo por um lado e as coleções por outro. As pessoas, as instituições, criam arquivos e formam coleções sem se preocuparem em desenvolver uma reflexão sobre o conteúdo arquivado, não há uma escritura. Fica o lugar pleno de objetos e documentos e, ao mesmo tempo, vazio de significação. Como o lugar pleno, vive de coleções de arquivos, de documentos, de fotocópias, torna-se um museu de um museu.

É neste momento que se percebe que a instituição perde o caminho da reflexão em função do caminho do arquivista. Nesta tensão entre a falta e o excesso, tem-se um lugar vazio. Tem-se um lugar pleno de objeto, mas falta a inscrição, a escritura. Se se considerar os processos de musealização como operações museais, ou seja, no sentido de uma produção de documentação, que pode ser operações específicas realizadas no interior da instituição como ações de indexação, fichas catalográficas e outras, tudo isso pode formar um museu do museu. $\bigcirc$ que é em parte $o$ administrativo, que cria diferentes arquivos sobre

9 Para Freud um traço mnêmico é como um resto, um resíduo de percepção que daria lugar à várias inscrições. Essa percepção está associada ao inconsciente uma vez que para ele memória e consciência são incompatíveis. "Assim se constitui o tesouro das lembranças, entreposto da memória, depósito de sentimentos, em que residem traços de acontecimentos, cenas e sensações, coisas vividas ou ouvidas, experiências de satisfação assim como de dor ou de pavor, mas também os representantes da atividade pulsional [...]" (SALVAIN, 1996, p.547). O que interessa nesse contexto dos estudos entre memória e arquivo é perceber que esses traços podem ser reativados e sua atualização fará com que o recalcado (uma percepção, uma ilusão) tenha crédito. 
as coleções gerando o arquivo-obra, são duplicações que, no interior do museu, pode ser acessado por um banco de dados gerados pelo sistema administrativo. Tem-se livro de tombo, mas se tem também, uma infinidade de fichas que gera o processo de escritura do objeto na instituição.

No contexto do mal de arquivo, analisado por Derrida (200I) e Roudinesco (2006), ver-se-á se esse arquivo institui ou não o excesso, o excesso de memória e suas implicações que constituem a falta de operações museais que organizam outras formas de arquivo. Tem-se excesso de memória, mas na verdade não tem uma escritura do museu, uma inscrição de memória. A memória se encontra pulverizada em uma série de arquivos inoperantes e que só poderão ser acessados pelo rastro.

Neste contexto, Roudinesco (2006) afirma que em muitas instituições se deparam com manuscritos que não foram classificados, não possuem uma organização, um repertório ou depósito, uma organização dos dados, não se constituindo, assim, em arquivo, e sim, na falta dele.A falta de arquivo é, para ela, tão tirânica quanto o excesso, criando o sintoma de história que vai se apagando, um constante apagamento de vestígio. Quanto mais se apaga o vestígio, mais se constrói uma ordem imaginária fundada na impossibilidade de se remeter a um repertório, no caso, é uma ordem imaginária da contemporaneidade. Cria-se uma espécie de ficção. Cria-se a fantasmagoria do arquivo, o mal de arquivo (DERRIDA, 200I).

O que se observa é que a leitura do arquivo, seu tratamento, ou sua exegese é de certa forma uma violência sobre o mesmo. É preciso não só arquivar, mas possibilitar a sua escritura, a sua compreensão. $O$ arquivo não pode se tornar unol0 se designar numa unicidade, isso seria uma violência. $O$ arquivo deve ser re-con-signadol I, pois ele é processual. $O$ problema não está só no excesso ou na falta do arquivo, e sim, na escritura, no processo de inscrição que é permanente e dinâmico.

Assim, ao se analisar o arquivo sob o viés do mal de arquivo, no conceito de Derrida (200l), compreende-se que, o mal de arquivo se baseia no mal-estar que está centrado no conceito metapsicológico da pulsão de morte freudiana, em algo que nos impulsiona a conhecer a origem de todo o processo de arquivamento e construção da memória. Ou seja, como se viu no conceito de mal-estar, a pulsão de morte é um desejo de viver, é uma pulsão organizadora. No arquivo ela consiste no desejo de ordenação, de escrituração, de inscrição.

Se se considerar o âmbito da arte contemporânea, é possível perceber que a produção contemporânea por si só já é musealizável, uma produção que nasce gerando arquivos. A cada exposição, ou processos de visibilidade, que a obra do acervo é submetida, produz-se ou deveria produzir o arquivamento de sua trajetória, principalmente se forem obras em que o próprio corpo do artista é a obra, como a performance. Esse tipo de poética no museu abre caminhos para uma série de arquivos paralelos que vão, a partir de sua exponibilidade e consequente valoração, se transformando em arquivo-obra.

É assim, no escopo da produção artística que a cada dispositivo de exibição, de estudo e manuseio deste complexo arquivístico, gera, como afirmou Costa (2008) a fantasmagoria do "mal de arquivo". É ainda, no interior da instituição, que esse arquivo deve ser arguido, deve passar por uma escritura, ser organizado, analisado em sua origem. É assim, diante de sua destruição e recu-

10 Roudinesco (2006) observa, a partir do acervo do Museu de Freud, que se apenas um certo grupo tem acesso a informação, ou que este arquivo está protegido por uma certa unicidade de pensamento, de leitores, tradutores, há sua dogmatização. Ele se transforma em Uno.

II Arquivo reconsignado é também re-com-signar, trazer novos signos que muitas vezes o distancia de sua origem. É o que ocorre quando este se encontra sob a guarda dos arcônticos. 
peração, escritura e esquecimento, que o mal de arquivo revitaliza a escrita da história e constitui os lugares de memória.

\section{Referências}

CHAGAS, Mario. Há uma gota de sangue em cada museu: a ótica museológica de Mario de Andrade. Chapecó:Argos, 2006.

DERRIDA, Jacques. Mal de arquivo: uma impressão freudiana. Tradução Claudia de Moraes Rego. Rio de Janeiro: Relume Dumará, 200 I.

DIDI-HUBERMAN, Georges. O que vemos o que nos olha. Tradução Paulo Neves. São Paulo: Ed. 34, 1998.

FREUD, Sigmund. O mal-estar na civilização. Tradução José Octávio de Aguiar Abreu. Rio de Janeiro: Imago, 1997.

HUYSSEN,Andrea. Escapando da amnésia: o museu como cultura de massa. In:MEMÓRIAS do modernismo.Tradução Patrícia Farias. Rio de Janeiro: Editora da UFRJ, 1996.

INSTITUTO BRASILEIRO DE MUSEUS. Site. Disponível em: <wwwl.museus. gov.br/>.Acesso em: I5 ago. 2010.

LOURENÇO, Maria Cecília França. Museus acolhem o moderno. São Paulo: Universidade de São Paulo, 1999.

NORA, Pierre. Entre memória e história a problemática dos lugares. Tradução Yara Aun Khoury. Projeto História: Revista do Programa de Estudos em História e do Departamento de História da PUC-SP, São Paulo, n. I0, p. 07-28, dez. 1993. Disponível em: <http://www.pucsp.br/projetohistoria/downloads/revista/ PHistoria 10. pdf>. Acesso em: 22 mar. 2010.

POLLACK, Michael. Memória, esquecimento, silêncio. Estudos Históricos, Rio de Janeiro, v. 2, n.3, p. 3-I5, 1989.

ROUDINESCO, Elisabeth. A análise e o arquivo. Rio de Janeiro: Jorge Zahar, 2006.

SALVAIN, P.Traço. Dicionário enciclopédico de psicanálise: o legado de Freud e Lacan. Tradução Vera Ribeiro, Maria Luiza X. de A. Borges. Rio de Janeiro: Jorge Zahar, 1996. p. 547-548.

SELIGMANN-SILVA. Márcio (Org.). Palavra e imagem: memória e escritura. Chapecó:Argos, 2006.

WINTER, Jay. A geração da memória: reflexões sobre o boom da memória nos estudos contemporâneos de história. In: SELIGMANN-SILVA, Márcio. Palavra e imagem: memória e escritura. Chapecó:Argos, 2006. 